\title{
Targeting $\mathrm{Bcl}-2 / \mathrm{Bcl}-\mathrm{X}_{\mathrm{L}}$ Induces Antitumor Activity in Uveal Melanoma Patient-Derived Xenografts
}

\author{
Fariba Némati ${ }^{1}$, Catherine de Montrion ${ }^{2}$, Guillaume Lang ${ }^{1}$, Laurence Kraus-Berthier ${ }^{3}$, Guillaume Carita ${ }^{1}$, \\ Xavier Sastre-Garau ${ }^{4}$, Aurélie Berniard', David Vallerand' ${ }^{1}$, Olivier Geneste ${ }^{3}$, Ludmilla de Plater', \\ Alain Pierré ${ }^{2}$, Brian Lockhart ${ }^{2}$, Laurence Desjardins ${ }^{5}$, Sophie Piperno-Neumann ${ }^{6}$, Stéphane Depil ${ }^{2,3}$, \\ Didier Decaudin ${ }^{1,6 *}$
}

1 Laboratory of Preclinical Investigation, Department of Translational Research, Institut Curie, Paris, France, 2 I.D.R.S., Institut de Recherches Servier, Croissy, France, $\mathbf{3}$ I.R.I.S., Institut de Recherches International Servier, Suresnes, France, 4 Department of Tumor Biology, Institut Curie, Paris, France, $\mathbf{5}$ Department of Ophthalmological Oncology, Institut Curie, Paris, France, 6 Department of Medical Oncology, Institut Curie, Paris, France

\begin{abstract}
Purpose: Uveal melanoma (UM) is associated with a high risk of metastases and lack of efficient therapies. Reduced capacity for apoptosis induction by chemotherapies is one obstacle to efficient treatments. Human UM is characterized by high expression of the anti-apoptotic protein $\mathrm{Bcl}-2$. Consequently, regulators of apoptosis such as $\mathrm{Bcl}-2$ family inhibitors may constitute an attractive approach to UM therapeutics. In this aim, we have investigated the efficacy of the Bcl-2/Bcl- $\mathrm{X}_{\mathrm{L}}$ inhibitor S44563 on 4 UM Patient-Derived Xenografts (PDXs) and derived-cell lines.

Experimental Design: Four well characterized UM PDXs were used for in vivo experiments. S44563 was administered alone or combined with fotemustine either concomitantly or after the alkylating agent. $\mathrm{Bcl}-2, \mathrm{Bcl}-\mathrm{X}_{\mathrm{L}}$, and $\mathrm{Mcl}-1$ expressions after S44563 administration were evaluated by immunohistochemistry (IHC).

Results: $\$ 44563$ administered alone by at 50 and $100 \mathrm{mg} / \mathrm{kg}$ i.p. induced a significant tumour growth inhibition in only one xenograft model with a clear dose effect. However, when S44563 was concomitantly administered with fotemustine, we observed a synergistic activity in 3 out of the 4 tested models. In addition, S44563 administered after fotemustine induced a tumour growth delay in 2 out of 3 tested xenografts. Finally, $\mathrm{IHC}$ analyses showed that $\mathrm{BCl}-2, \mathrm{Bcl}-\mathrm{X}_{\mathrm{L}}$, and $\mathrm{Mcl}-1$ expression were not modified after $\mathbf{5} 44563$ administration.

Conclusion: The novel anti-apoptotic experimental compound S44563, despite a relative low efficacy when administered alone, increased the efficacy of fotemustine in either concomitant or sequential combinations or indeed subsequent to fotemustine. These data support further exploration of potential therapeutic effect of $\mathrm{Bcl}-2 / \mathrm{Bcl}-\mathrm{xl}$ inhibition in human UM.
\end{abstract}

Citation: Némati F, de Montrion C, Lang G, Kraus-Berthier L, Carita G, et al. (2014) Targeting BCl-2/Bcl-X Induces Antitumor Activity in Uveal Melanoma PatientDerived Xenografts. PLoS ONE 9(1): e80836. doi:10.1371/journal.pone.0080836

Editor: Keiran Smalley, The Moffitt Cancer Center \& Research Institute, United States of America

Received September 4, 2013; Accepted October 16, 2013; Published January 13, 2014

Copyright: (C) 2014 Némati et al. This is an open-access article distributed under the terms of the Creative Commons Attribution License, which permits unrestricted use, distribution, and reproduction in any medium, provided the original author and source are credited.

Funding: The study was supported by Servier Laboratories. However, the funders had no role in study design, data collection and analysis, decision to publish, or preparation of the manuscript.

Competing Interests: CdM, LKB, AP, BL, and SD belong to the Servier Laboratories which develop the new Bcl-2/Bcl-XL inhibitor S44563. This work was supported by a commercial source 'Servier Laboratories' and one or more of the authors have an affiliation to the commercial funders of this research, 'Servier Laboratories'. This does not alter the authors' adherence to all the PLOS ONE policies on sharing data and materials.

* E-mail: Didier decaudin@curie net

\section{Introduction}

Uveal melanomas (UM) represent the most frequent intraocular tumour in adult patients. Whereas the 5 -year overall survival rate of localized disease is greater than $70 \%$, the prognosis drops dramatically in cases of metastases [1]. Up to $50 \%$ of patients will develop metastases within a median time of 2.4 years [2]. The overall survival is poor, and the majority of patients will succumb to their cancer. Systemic therapy with alkylating agents, i.e. fotemustine, dacarbazine, or temozolomide, have shown only modest efficacy [3]. Consequently, because of the limited efficacy of current treatments, new therapeutic strategies need to be developed.
One of the primary means by which UM cells evade treatmentinduced apoptosis is by up-regulation of members of the prosurvival Bcl-2 family proteins such as Bcl-2 and Bcl-XL $[4,5]$. Indeed, human uveal melanomas are characterized by a high average percentage of $\mathrm{Bcl}-2$ positive cells of $82 \%$ (range: $44 \%-100 \%$ ) [6-12], but without any prognostic impact $[6,9,10,12]$. This observation was also confirmed by the present group in a panel of primary human UM xenografts obtained from patient's tumors, where Bcl-2 was shown to be expressed in almost all studied patient's tumours and corresponding xenografts [13].

A variety of approaches to target these anti-apoptotic oncoproteins have been pursued in order to try and restore the natural process of programmed cell death [14], notably bcl-2 anti-sense oligonucleotides such as Oblimersen $\left(\right.$ Genasense $\left.^{\circledR}\right)$ with contrasted 
positive $[15,16]$ or negative $[17-19]$ impact in randomized clinical trials performed in cutaneous melanoma, chronic lymphoid leukemia, multiple myeloma, and prostate cancer patients. Another potential therapeutic approach consists of using small molecules that occupy the $\mathrm{BH} 3$ binding groove of antiapoptotic Bcl-2 family members (BH3 mimetics), including ABT-737 [20], ABT-263 (Navitoclax $\left.{ }^{\circledR}\right)$ [21], and GX15-070 (Obatoclax ${ }^{\circledR}$ ) [22]. These drugs disrupt Bcl-2/Bcl- $\mathrm{X}_{\mathrm{L}}$ interactions with pro-death proteins (e.g., Bim), leading to the initiation of apoptosis. In human tumor cells, BH3 mimetics induce Bax translocation, cytochrome c release, and subsequent apoptosis. In human xenograft models of small-cell lung cancer, multiple myeloma, lymphoblastic leukaemia, and aggressive B-cell lymphoma, Bcl-2/ $\mathrm{Bcl}-\mathrm{X}_{\mathrm{L}}$ inhibitors were previously shown to significantly enhance the efficacy of clinically relevant therapeutic regimens [21,23-25]. As relatively few clinical studies using these new compounds have been reported [26,27], no randomized clinical data are already available.

In contrast to the high number of reports in various hematologic and solid tumors including cutaneous melanoma, only one in vitro study has evaluated Bcl-2 targeting in uveal melanoma cells, showing synergistic effect with chemotherapy and multi-drug resistance reversion [28]. Based on this observation and considering the high Bcl-2 expression in UM and the occurrence of liver metastases in its natural history, we have evaluated the therapeutic potential of a new experimental Bcl-2/Bcl-X $\mathrm{X}_{\mathrm{L}}$ inhibitor, S44563, in different uveal melanoma Patient-Derived Xenografts (PDXs), and derived-cell lines, alone or in combination with fotemustine.

\section{Materials and Methods}

\section{Ethics statement}

Before PDX establishment, all patients had previously given their verbal informed consent for experimental research on residual tumor tissue available after histophatologic and cytogenetic analyses. Those PDXs establishments have been performed after approval of the ethics committee of the Institut Curie. According to the French rules and the ethics committee of the Institut Curie, a written consent from patients for obtaining residual tumor tissues is not required. In case of patient refusal that could be orally expressed or written, residual tumor tissues are not collected. All issues that patients want to be discussed could be raised at any time during any medical consultations. This procedure was approved by ethics committees. This research was not conducted outside of our country. Studies have been performed in compliance with the recommendations of the French Ethical Committee and under the supervision of authorized investigators. The experimental protocol and animal housing were in accordance with institutional guidelines as put forth by the French Ethical Committee (Agreement C75-05 - 18, France), and the ethics committee of the Institut Curie that approved this project.

\section{Compounds}

S44563 is a new Bcl-2/bcl- $\mathrm{X}_{\mathrm{L}}$ inhibitor. It potentially inhibits the anti-apoptotic proteins $\mathrm{Bcl}-2$ and $\mathrm{Bcl}-\mathrm{X}_{\mathrm{L}}$ by binding to their respective $\mathrm{BH} 3$ binding groove. $\mathrm{S} 44563$ was synthesized at IdRS (France) as described (initial patent application filed in France 02/ 02/2007 under $\left.\mathrm{N}^{\circ} 07 / 00741\right)$. S44563 $\left(\mathrm{C}_{44} \mathrm{H}_{47} \mathrm{CIN}_{6} \mathrm{O}_{5} \mathrm{~S}_{2}\right)$ has a molecular weight of 912.4 (chemical structure is presented in Figure S1). S44563-2 was synthesized at Institut de Recherches Servier. The purity of the batches ranges between $97.8 \%$ and $99.9 \%$, and the optical purity was $99 \%$. Fotemustine (Muphoran ${ }^{\circledR}$ ) was kindly provided from IRIS (France).

\section{Fluorescence polarisation assays}

A fluorescent $\mathrm{BH} 3$ peptide (BH3 motif from the protein Puma) was incubated with either recombinant $\mathrm{Bcl}-2$ or $\mathrm{Bcl}-\mathrm{X}_{\mathrm{L}}$ protein (20 mM Na $2 \mathrm{HPO}_{4} \mathrm{pH}$ 7.4, $50 \mathrm{mM} \mathrm{NaCl}, 1 \mathrm{mM}$ EDTA, 0.05\% pluronic acid). Upon binding, the fluorescence emitted by the BH3 peptide becomes polarised. The inhibition of the interaction between the fluorescent $\mathrm{BH} 3$ peptide and $\mathrm{Bcl}-2$ or $\mathrm{Bcl}-\mathrm{X}_{\mathrm{L}}$ is followed by measuring a decrease in fluorescence polarisation. In these assays, Bcl-2 or $\mathrm{Bcl}-\mathrm{X}_{\mathrm{L}}$ concentration was $100 \mathrm{nM}$, the fluorescent $\mathrm{BH} 3$ peptide concentration was $15 \mathrm{nM}$ and S44563-2 was titrated from $1 \mathrm{nM}$ to $100 \mu \mathrm{M}$.

\section{Uveal melanoma PDXs}

Three UM cell lines have been used, all derived from UM PDXs established from intraocular lesion (MP41, MM26, and MM66). Four UM PDXs obtained from patients after enucleation (MP41 and MP77) or liver metastasis surgery (MM26 and MM66), established, characterized and maintained into SCID mice have been used $[13,29]$. The principal characteristics of these 4 xenografts are presented in the Table S1. We could not use each model in both in vitro and in vivo experiments, because some xenografts could not be maintained in prolonged in vitro cultures.

\section{In vitro experiments}

UM cell lines were routinely maintained in RPMI 1640 containing GlutaMAX ${ }^{\mathrm{TM}}$ (Invitrogen, Carlsbad, CA, USA), $20 \%$ fetal bovine serum (Invitrogen, Carlsbad, CA, USA) and $1 \%$ penicillin and streptomycin (Invitrogen, Carlsbad, CA, USA). Flasks of $75 \mathrm{~cm}^{3}$ were incubated at $37^{\circ} \mathrm{C}$ in humidified $5 \% \mathrm{CO}_{2}$ until $85 \%-95 \%$ confluence was attained. Thereafter, cells were seeded $\left(2 \times 10^{5}\right.$ cells $\left./ \mathrm{ml}\right)$ in 96 -well plates, incubated $24 \mathrm{~h}$ at $37^{\circ} \mathrm{C}$, and then treated with different doses of S44563 (dissolved at 20\% DMSO and diluted with $0.9 \%$ sodium chloride at $20 \mathrm{mg} / \mathrm{ml}$ ) (Servier, Courbevoie, France). The cells were incubated for $24 \mathrm{~h}$ at $37^{\circ} \mathrm{C}$.

Cell viability was determined with WST-1 assay (Roche, Indianapolis, USA). The culture medium was replaced with a medium containing a WST-1 reagent, and $1 \mathrm{~h}$ later, the absorbance in the well was determined at $450 \mathrm{~nm}$ with a reference wavelength of $620 \mathrm{~nm}$ by using a microplate reader TECAN Infinite M200 (TECAN Deutschland GmbH, Crailsheim, Germany, Software Magellan $\left.{ }^{\mathrm{TM}}\right)$. The percentage of viability was evaluated by $\Delta \mathrm{OD}_{(540-620)}$ treated $/ \Delta \mathrm{OD}_{(540-620)}$ control $\times 100$. The $50 \%$ growth inhibitory concentration $\left(\mathbf{I C}_{50}\right)(50 \%$ inhibitory concentration) was then defined for each drug and cell line.

For determination of apoptosis, mitochondrial transmembrane potential $(\Delta \Psi \mathrm{m})$ and cell cycle, cells were incubated with $\mathrm{S} 44563$ at a concentration of 17 and $34 \mu \mathrm{M}$ for $24 \mathrm{~h}$. The detection of apoptosis and $\Delta \Psi \mathrm{m}$ alterations was done by the protocol $\mathrm{AbC}$ Annexin 5/FITC kit (AbCys, Paris, France) and BD ${ }^{\mathrm{TM}}$ MitoScreen kit (BD Biosciences, San Jose, CA, USA) respectively with DAPI (1/200, Invitrogen, Carlsbad, CA, USA). The study of the cell cycle by propidium iodure (1/100, Sigma-Aldrich Chemie, Saint-Quentin Fallavier, France) was performed after fixing cells with ethanol $70 \%$ and permeabilization with RNase A (1/100, Roche, Indianapolis, IN).

Cell autophagy was assessed by detecting cleaved and noncleaved LC3 [30], cells were seeded and treated by 2 and $4 \mu \mathrm{M}$ of S44563 in 6-well plates for 24 hours. Cell pellets were lysed in $30 \mu \mathrm{l}$ of boiling Laemmli lysis buffer [ $50 \mathrm{mM}$ Tris $\mathrm{pH}=6.8,2 \%$ SDS, 5\% glycerol, 2 mM DTT, 2.5 mM EDTA, 2.5 mM EGTA, qsp $\mathrm{H}_{2} \mathrm{O}$, Phosphatase inhibitor $1 \times($ Halt Phosphatase inhibitor cocktail, Perbio Science France, Brebières, France), protease inhibitors 1 tablet/10 ml (Protease inhibitor cocktail, complete 
MINI EDTA-free, Roche, Indianapolis, IN), 2 mM Orthovanadate of Sodium and $10 \mathrm{mM}$ Sodium Fluoride]. Total proteins were determined by BCA Protein assay kit reducing Agent compatible (Perbio Science France, Brebières, France). Total proteins were separated by Invitrogen gel 12\% (Buffer NuPAGE MES $1 \times$ and anti-oxydant, Invitrogen, Carlsbad, CA, USA), transferred to nitrocellulose membranes and analyzed by immunoblotting using the ECL method (ECL Western Blotting Detection Reagents, GE Healthcare Life Sciences GmbH, Velizy-Villacoublay, France). The following primary antibodies were used: anti-LC3B antibody produced in rabbit $(1 / 500$, SigmaAldrich Chemie, Saint-Quentin Fallavier, France), anti- $\beta$-actin antibody produced in mouse (1/5000, Sigma-Aldrich Chemie, Saint-Quentin Fallavier, France). Polyclonal goat anti-rabbit (1/ $5000)$ and anti-mouse $(1 / 10000)$ secondary antibody conjugated horseradish peroxidase (HRP) were purchased from Dako France (Trappes, France) and Jackson ImmunoResearch Laboratories (West Grove, PA, USA) respectively. The signals were detected by LAS-3000 imager (Fujifilm, Odawara, Japan). Membranes were exposed during 5 minutes. The quantity of cleaved (active) and inactive (non-cleaved) LC3 was related to $B$ actin.

All results were statistically analyzed by two-way ANOVA test with Bonferroni post-test versus control group. Data were represented as mean \pm standard error of mean $(n=3-5$ replicates). $\mathrm{p}<0.05$ were considered significant $(*)$.

\section{In vivo experiments}

SCID mice, 4 to 6 weeks old, bred at Curie Institute, were used for in vivo experiments. Fragments of $30-60 \mathrm{~mm}^{3}$ were grafted subcutaneously into the interscapular fat pad. When tumors reached a size of $60-200 \mathrm{~mm}^{3}$, mice were randomly assigned to the control or treatment groups and treatment was started on day 1. Between 8 to 12 mice per group were included in in vivo experiments. Tumor growth was evaluated by measurement of two perpendicular diameters of tumors with a caliper, twice a week. Individual tumor volume, relative tumor volume (RTV), and tumor growth inhibition (TGI) were calculated according to standard methodology [13]. Statistical significance of TGI was calculated by the paired Student's t-test. Xenografted mice were sacrificed when their tumor reached a volume of $2500 \mathrm{~mm}^{3}$.

For in vivo administration, S44563 was diluted in polysorbate $80 /$ water $10 \%$.and was administered at a dose of 50 or $100 \mathrm{mg} / \mathrm{kg}$ alone, concomitantly (days 1-5/8-12/22-26/29-33) and/or after (days 43-47/50-54/64-68/70-74) fotemustine administration (15 or $30 \mathrm{mg} / \mathrm{kg}$ days 1 and 22). All treatments were administered intraperitoneally.

In all in vivo experiments, a relative tumor volume variation (RTVV) of each S44563-treated mouse was calculated from the following formula: $[(\mathrm{Vt} / \mathrm{Vc})-1]$, where $\mathrm{Vt}$ is the volume of the treated mouse and $\mathrm{V}_{\mathrm{c}}$ the median volume of the corresponding control group at a time corresponding to the end of treatment.

\section{Immunohistochemical studies}

All immunohistochemistry protocols were realized automatically on a Ventana ${ }^{\mathrm{TM}}$ Discovery XT machine with neutral buffered formalin-fixed $(4 \%)$ tissue sections of paraffin-embedded tumor biopsies. In each case, $5-\mu \mathrm{m}$ sections were pre-treated with standard CGl reagent (Ventana ${ }^{\mathrm{TM}}$ Tris/Borate/EDTA buffer $\mathrm{pH}$ 8- $48 \mathrm{~min}-95^{\circ} \mathrm{C}$ ) for Bcl-2,) or mild CGl (28 min) for Mcl-1 and with standard CC2 reagent (Ventana ${ }^{\mathrm{TM}}$ Citrate buffer $\mathrm{pH} 6$ $48 \mathrm{~min} 95^{\circ} \mathrm{C}$ ) for Bcl-XL, cleaved Caspase 3, and LC3B. Endogenous biotin blocking was carried out for all antibodies detections $(8 \mathrm{~min})$. The following primary antibodies were used: rabbit monoclonal anti-human Bcl-2 (clone E17) from Epitomics (ref 1017-1) dilution 1:100, 60 min incubation; rabbit monoclonal anti-human Bcl-X $\mathrm{L}_{\mathrm{L}}$ (clone 54H6) from Cell Signaling Technology (ref 2764) dilution 1:150, $60 \mathrm{~min}$ incubation; rabbit polyclonal anti-human Mcl-1 from Sigma (ref HPA008455 dilution 1:80, 60 min incubation; rabbit monoclonal anti-human cleaved caspase 3 (clone C92-605) from Pharmingen (ref 559565) dilution 1:100, 32 min incubation; rabbit monoclonal anti LC3B (clone D11) from Cell Signaling Technology (ref 3868) dilution 1:100 $60 \mathrm{~min}$ incubation. Biotinylated donkey anti rabbit $\mathrm{IgG}$ from Jackson Immunoresearch (ref 711-065-152) was added in sequence (dilution 1:100 $32 \mathrm{~min}$ incubation. Excepted for Caspase 3 and LC3B detections on MM26 and MP41, a chromogen substrate (DAB diaminobenzidine-biotin-peroxidase) was added to each specimen according the manufacter's instructions. Finally, sections were counter-stained (hematoxylin: $8 \mathrm{~min}$ ) and post counterstained (bluing reagent: $8 \mathrm{~min}$ ). For caspase 3 and LC3B detections on MM26 and MP41 tumours the chromogenic system was NBT/BCIP and sections were counter-stained with Nuclear Fast Red. All the incubations were performed at $37^{\circ} \mathrm{C}$ with the exception of pre-treatments $\left(95^{\circ} \mathrm{C}\right)$.

Intensity and percentage of positive stained (DAB) cells were then quantified by an anatomopathologist (Dr J.F. Boivin). Two parameters were used to evaluate $\mathrm{Bcl}-2, \mathrm{Bcl}-\mathrm{X}_{\mathrm{L}}$, and $\mathrm{Mcl}-1$ expression: semi-quantitative visual grading system of the intensity of staining ( - , negative; +, weak; ++ modest; +++ strong), and the percentage of labelled tumor cells. To integrate these two parameters, a $\mathrm{H}$-score (histological score) was calculated as $\mathrm{H}$ score $=$ tumor cell staining percentage $\times$ staining intensity. One parameter (percentage of labeled tumor cells) was used to evaluate cleaved Caspase 3.

\section{Results}

\section{Inhibition of $\mathrm{BCl}-2$ and $\mathrm{BCl}-\mathrm{X}_{\mathrm{L}}$ binding to a $\mathrm{BH} 3$ peptide by S44563}

Inhibition of $\mathrm{Bcl}-2$ and $\mathrm{Bcl}-\mathrm{X}_{\mathrm{L}}$ was investigated by fluorescence polarisation (FP) assays using recombinant $\mathrm{Bcl}-2$ or $\mathrm{Bcl}-\mathrm{X}_{\mathrm{L}}$ and a fluorescent Puma BH3 peptide. The Figures $1 \mathrm{~A}$ and $1 \mathrm{~B}$ show the inhibition of Bcl-2 and Bcl- $\mathrm{X}_{\mathrm{L}}$ respectively by $\mathrm{S} 44563$. S44563 is a potent inhibitor of $\mathrm{Bcl}-2$ and $\mathrm{Bcl}-\mathrm{X}_{\mathrm{L}}$. Its $\mathrm{IC}_{50 \mathrm{~s}}$ in a $\mathrm{Bcl}-2 / \mathrm{F}$ PumaBH3 interaction assay and a $\mathrm{Bcl}-\mathrm{X}_{\mathrm{L}} / \mathrm{F}-\mathrm{PumaBH} 3$ interaction assay were $131 \mathrm{nM} \quad[123 \mathrm{nM} ; 135 \mathrm{nM}]$ and $140 \mathrm{nM}$ [133 nM;150 nM], respectively.

\section{$\mathrm{Bcl}-2, \mathrm{Bcl}-\mathrm{X}_{\mathrm{L}}$, and $\mathrm{Mcl}-1$ expression in uveal melanoma PDXs}

The determination of the expression of Bcl-2, Bcl- $\mathrm{X}_{\mathrm{L}}$, and Mcl1 was performed in 3 to 5 different tumors for each model. The expression of Bcl-2 was high for $3 \mathrm{UM}$ xenografts used for in vivo experiments (MP41, MP77, and MM26), where the median Hscore ranged between 150 and 175, and low for the MM66 model for which the median Bcl-2 H-score was lower than 5 (Table S2) (Figure 2). In contrast, Bcl- $\mathrm{X}_{\mathrm{L}}$ was highly expressed in the MP41 xenograft (H-score of 175) and not or slightly expressed in the 3 remaining models (Table S1) (Figure 2). Finally, Mcl-1 was expressed in a high proportion of tumor cells of all studied xenografts, except for the MM66 xenograft, but with a relative weak intensity (Table S1) (Figure 2). A global IHC score was then defined, including $\mathrm{Bcl}-2, \mathrm{Bcl}-\mathrm{X}_{\mathrm{L}}$, and $\mathrm{Mcl}-1$ protein expression, as: (Bcl-2 score $)+\left(\mathrm{Bcl}-\mathrm{X}_{\mathrm{L}}\right.$ score $) / \mathrm{Mcl}-1$ score. The median global score differed among the 4 studied models, i.e. 3.25 for the MP41 xenograft, 1.19 for the MP77 model, 2.06 for the MM26 xenograft, and 0.33 for the MM66 model. 

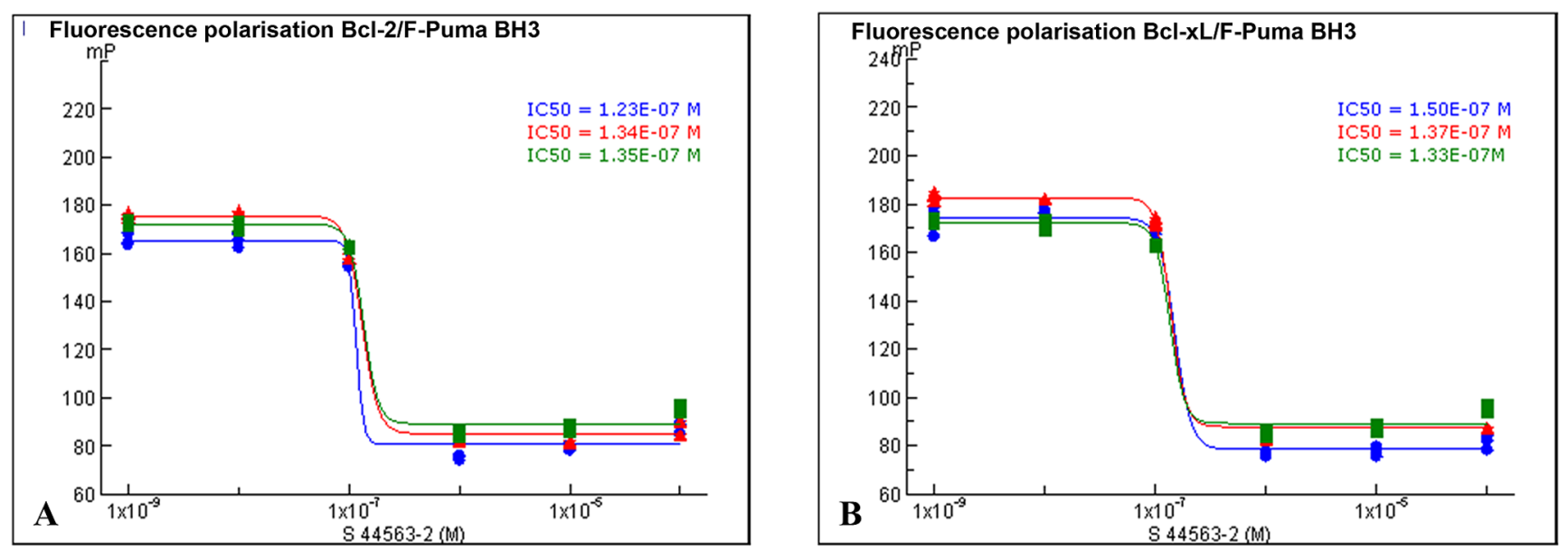

Figure 1. Inhibition of the interaction between $\mathrm{Bcl}-2$ or $\mathrm{Bcl}-\mathrm{X}_{\mathrm{L}}$ and fluorescent Puma $\mathrm{BH} 3$ peptide measured by the decrease of fluorescence polarisation as a function of S44563-2 concentration. Three independent experiments are presented. FP data are presented in millipolarization units (mP). For each experiment, measures are assessed in triplicate.

doi:10.1371/journal.pone.0080836.g001

\section{In vitro studies}

For the 3 uveal melanoma xenograft-derived cell lines MP41, MM26, and MM66 incubated with increased concentrations of S44563, $17 \mu \mathrm{M}$ and $34 \mu \mathrm{M}$ for 24 hours, the IC50s were $4 \mu \mathrm{M}$, $7 \mu \mathrm{M}$, and $6 \mu \mathrm{M}$ for the MP41, MM26, and MM66 cell lines, respectively (Figure S2). Similarly, to evaluate apoptosis induction, the MP41, MM26, and MM66 cell lines were incubated with $17 \mu \mathrm{M}$ and $34 \mu \mathrm{M}$ S44563 for 24 hours, after which the samples were labeled with DAPI/annexin V-FITC or JC1. We observed apoptosis induction and a drop of the $\Delta \Psi \mathrm{m}$ in the $3 \mathrm{UM}$ cell lines, although the effects were less important in the MM26 cell line (Figure 3A and 3B). Similarly, in the two UM cell lines MP41 and MM66 that are more sensitive to S44563, we observed a significant decrease of the $\mathrm{G} 2 / \mathrm{M}$ phases which were not modified in the less sensitive MM26 cell line (Figure 3C).

To study the impact on autophagy induction of S44563, the 3 UM cell lines were cultured with non-apoptotic doses of S44563 (2 and $4 \mu \mathrm{M}$ for 24 hours). The amount of active (cleaved form) and inactive (non-cleaved form) protein LC3 was measured by western blotting. We observed that both the proportion and the total amount of cleaved LC3 protein relative to $\beta$-actin, were not significantly modified after S44563 administration in the 3 studied UM cell lines (Figure 3D).

\section{In vivo experiments}

In the 4 UM PDXs, S44563 administered alone at 50 and $100 \mathrm{mg} / \mathrm{kg}$, for 2 cycles of treatment (5 days a week for 2 weeks and 1 week off, each cycle), induced a significant antitumor effect in one model (MP41), with a dose-dependent response and an optimal TGI of $61 \%$ at day 53 after start of treatment (Table 1) (Figure 4A). To evaluate responses to S44563 observed in the 4 models according to individual mouse variability, we decided to consider each mouse as one tumor-bearing entity. In this, when relative tumor volume variation [(RTVV)-1] of each S44563treated mouse was calculated, regardless of the doses of S44563, we observed that $68 \%$ of all S44563-treated mice (59/87) had a negative ratio compared to control groups, and that $22 \%$ had a ratio lower than $50 \%$, which constitute the threshold to consider a

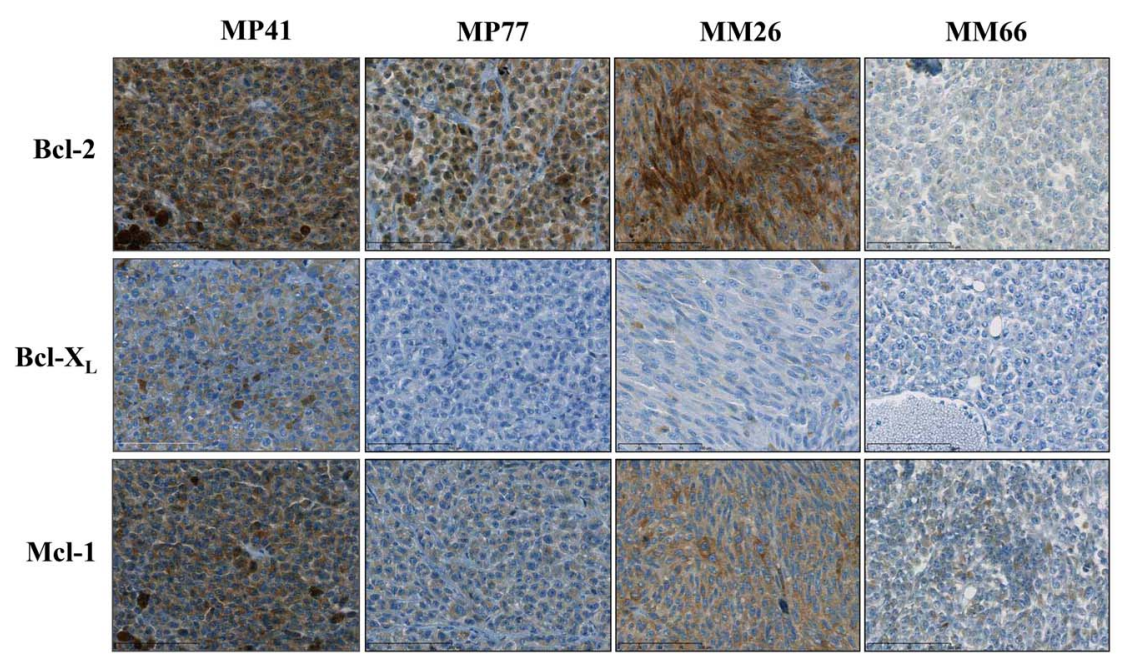

Figure 2. Bcl-2, Bcl- $\mathrm{X}_{\mathrm{L}}$, and $\mathbf{M c l}-1$ Immunohistochemistry. $\mathrm{BCl}-2, \mathrm{BCl}-\mathrm{X}_{\mathrm{L}}$, and $\mathrm{Mcl}-1$ expression determined by immunohistochemical analyses of the 4 human UM xenografts (between 3 to 5 tumors have been studied per condition). doi:10.1371/journal.pone.0080836.g002 


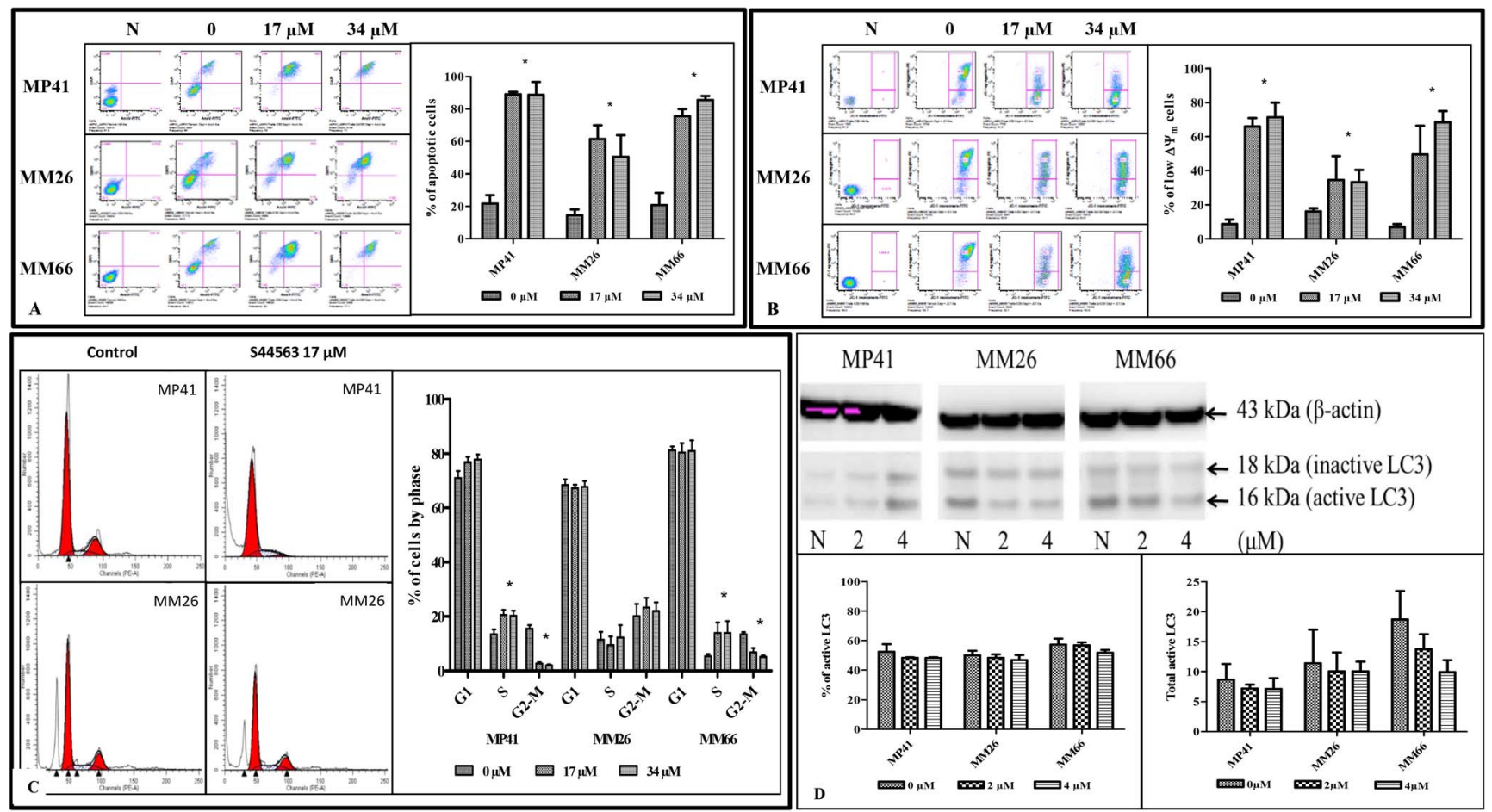

Figure 3. In vitro apoptosis induction by S44563. A and B. Apoptosis induction by S44563. The MP41, MM26, and MM66 cell lines were incubated with $17 \mu \mathrm{M}$ and $34 \mu \mathrm{M}$ S44563 for 24 hours, after which the samples were labeled with DAPI/annexin V-FITC (A) or JC1 (B). The proportion of annexin V-positive cells and low $\Delta \psi_{\mathrm{m}}$ cells was indicated in $\mathrm{C}$ and $\mathrm{E}$, respectively. A two-way ANOVA with Bonferroni post-test was then performed $(* \mathrm{p}<0.05)$. C. Cell cycle analyses after $\$ 44563$ exposure (17 or $34 \mu \mathrm{M}$ for $24 \mathrm{~h}$ ) in the $3 \mathrm{UM}$ cell lines. Cell cycle analysis was determined by labeling the DNA with propidium iodide. Each of the three lines was treated by $17 \mu \mathrm{M}$ or $34 \mu \mathrm{M}$ of S44563. The proportion of cells (\%) in different cell cycle phases was compared with the control (untreated). Two-way ANOVA with Bonferroni post-test was then performed (* means a $p<0.05)$. D. Cell cycle analyses of the xMP41 UM cell line. I and J. Measurement of autophagy on the 3 UM cell lines after S44563 exposure ( 2 or $4 \mu \mathrm{M}$ for $24 \mathrm{~h}$ ). After S44563 treatment, the amount of active and inactive protein LC3 was determined and reported to B-actine. The quantity of total LC3 protein was calculated to study the activation of LC3. Results were presented as percentage and total amount of active cleaved LC3, relative to $\beta$-actin. A two-way ANOVA with Bonferroni post-test was then performed (* means a $\mathrm{p}<0.05$ ).

doi:10.1371/journal.pone.0080836.g003

model as responding. Moreover, the overall response rate (RTVV $\leq 50 \%$ ) was $11 \%$ for the $50 \mathrm{mg} / \mathrm{kg}$ per injection of S44563, and $32 \%$ for the $100 \mathrm{mg} / \mathrm{kg}$ dose $(\mathrm{p}<0.05)$, confirming the dose-dependent efficacy of the $\mathrm{Bcl}-2 / \mathrm{Bcl}-\mathrm{X}_{\mathrm{L}}$ inhibitor (Figures 3A and S3B).

We then evaluated administration of both $\mathrm{S} 44563$ and fotemustine (Tables 1 and 2). In the MP41 xenograft, a tumor growth delay was observed in the 3 groups of combined treatments, i.e. concomitant fotemustine/S44563, fotemustine first then S44563 since day 43, and concomitant fotemustine/S44563 then S44563 since day 43 (data not shown). The median OS was 44 days for the control group, 67 days for the S44563 group, 72 days for the fotemustine group, and 102 days for the fotemustine+S44563 (whatever the schedule of combination) $\left(\mathrm{p}<10^{-3}\right)$ (Figure 4B). In the MP77 xenograft, concomitant S44563 $(100 \mathrm{mg} / \mathrm{kg}$ per injection) and fotemustine $(15 \mathrm{mg} / \mathrm{kg})$ induced a more significant TGI at day 35 after start of treatment than fotemustine alone $(p=0.04)$ (Figure 4C). Moreover, an increased median overall survival was observed when S44563 was administered in an adjuvant setting after fotemustine-induced complete remission. In the MM26 xenograft, concomitant S44563 (50 mg/ $\mathrm{kg}$ per injection) and fotemustine $(30 \mathrm{mg} / \mathrm{kg}$ ) slightly improved the TGI in comparison to fotemustine alone, but significantly improved the complete remission rate $(p<0.02)$ (Table 2$)$. In contrast, because of the occurrence of toxic deaths when S44563 was administered after fotemustine since day 43, we have not observed prolonged survival. This toxicity was observed in the only one MM26 model and could not be clearly explained due to its restrictive occurrence in the MM26 UM PDX. Finally, in the MM66 xenograft, concomitant S44563 (50 mg/kg per injection) and fotemustine $(30 \mathrm{mg} / \mathrm{kg})$ significantly enhances efficacy compared to treatment with either agent alone $(p<0.003)$ (Figure 4D).

\section{Correlations between IHC expressions and ORR to S44563}

We then evaluated correlations between histopathological analyses and response to S44563. We first showed that high Bcl2 expressing tumors could be either sensitive or resistant to S44563 administered alone (Figure 2 and Table 1). A similar observation could be done for high Mcl-1 expressing tumors. In contrast, only MP41 xenograft with a high $\mathrm{Bcl}-\mathrm{X}_{\mathrm{L}}$ expression was sensitive to S44563, whereas the 3 other models characterized by a low Bcl$\mathrm{X}_{\mathrm{L}}$ expression were resistant to $\mathrm{S} 44563$ administered alone. However, because of the limited number of tested xenografts, it was not possible to determine the relation between the global pathological score, defined as: (Bcl-2 score $)+\left(\mathrm{Bcl}-\mathrm{X}_{\mathrm{L}}\right.$ score $) / \mathrm{Mcl}-1$ score, and responses to $\mathrm{S} 44563$.

\section{Immunohistochemical studies after S44563 administration}

In order to evaluate the impact of S44563 on the expression of Bcl-2, Bcl- $\mathrm{X}_{\mathrm{L}}$, and Mcl-1 proteins, two to four tumor samples have 

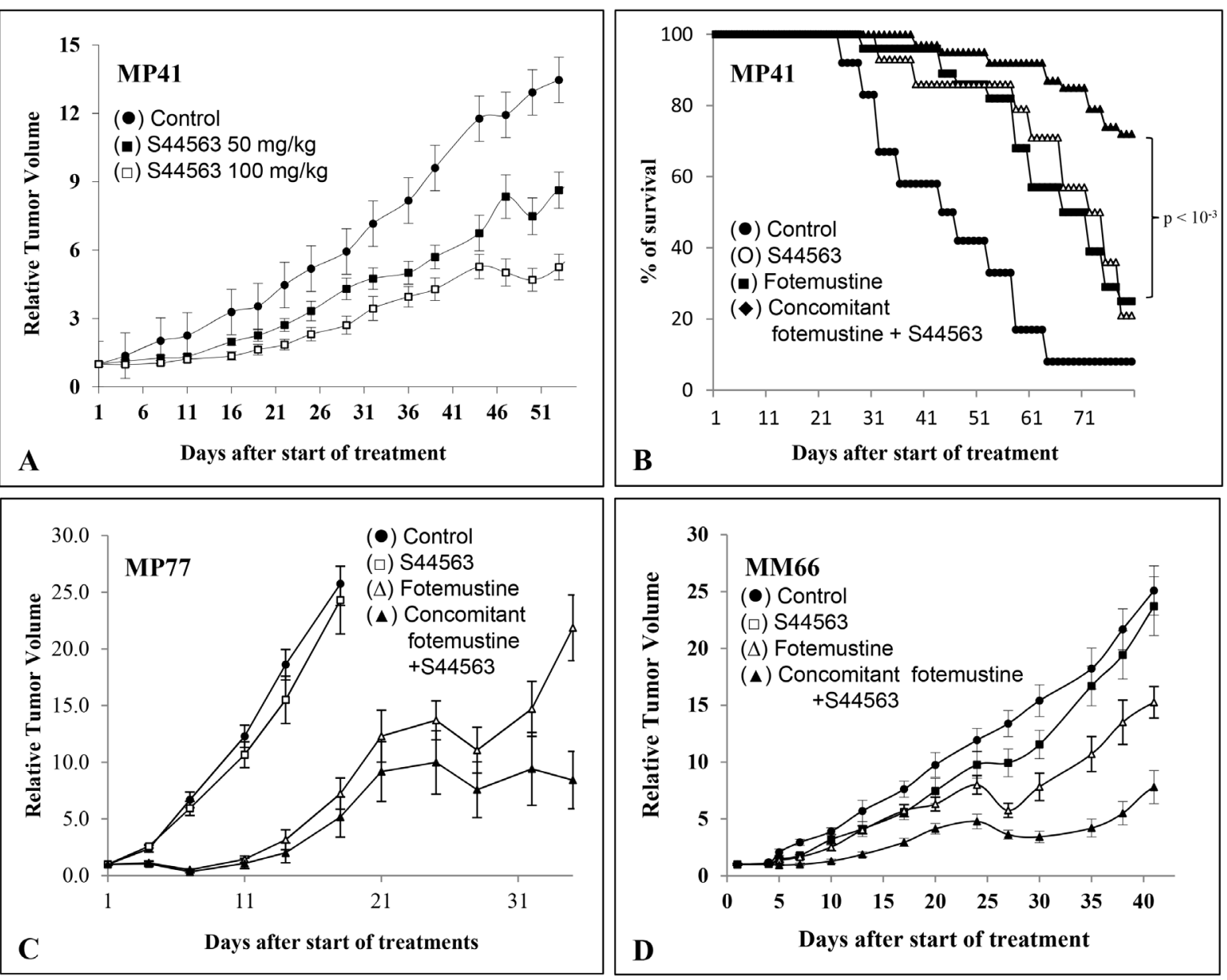

Figure 4. In vivo responses of UM PDXs to S44563 administered alone or in combination with fotemustine. A. MP41 xenograft was treated either by $\$ 44563$ at $50 \mathrm{mg} / \mathrm{kg}(\boldsymbol{\square})$ or $100 \mathrm{mg} / \mathrm{kg}(\square) 5$ days a week for 5 weeks. B. Overall survival of mice bearing MP41 tumors treated by S44563 (O), fotemustine ( $\mathbf{\square})$, and concomitant fotemustine+S44563 (\$). C. MP77 xenograft was treated by S44563 at $100 \mathrm{mg} / \mathrm{kg}(\square)$, fotemustine $15 \mathrm{mg} / \mathrm{kg}(\Delta)$, or both $(\boldsymbol{\Lambda})$. D. MM66 xenograft was treated by $\$ 44563$ at $50 \mathrm{mg} / \mathrm{kg}(\square)$, fotemustine $30 \mathrm{mg} / \mathrm{kg}(\Delta)$, or both $(\boldsymbol{\Lambda})$. Mice in the control group $(\mathbf{O})$ received $0,3 \mathrm{ml}$ of the drug-formulating vehicle with the same schedule as the treated animals. Tumor growth was evaluated by plotting the mean of the RTV (relative tumor volume) \pm SD per group. Between 8 to 12 mice per group were included in in vivo experiments. doi:10.1371/journal.pone.0080836.g004

been collected at the time of mice sacrifice for immunohistochemical studies. IHC analyses showed that Bcl-2, Bcl-X $\mathrm{X}_{\mathrm{L}}$, and Mcl-1 expressions were not modified after S44563 administration (Table S3) (Figure S4). Surprinsingly, we have observed that

Table 1. TGI and complete remission induced by a combination of S44563 and fotemustine.

\begin{tabular}{lllll}
\hline & & & & \\
\hline Treatments & MP41 & MP77 & MM26 & MM66 \\
\hline S-50 & 36 & 0 & 0 & 0 \\
S-100 & 61 & 12 & 10 & 6 \\
F-15 & $I$ & $\mathbf{7 2}$ & $I$ & $\mathbf{1 9}$ \\
F-15+S-100 & $I$ & $\mathbf{8 0}$ & $I$ & $\mathbf{4 0}$ \\
F-30 & 64 & $95(8 / 10)$ & $84(0)$ & 39 \\
F-30+S-50 & 73 & $99(8 / 10)$ & $97(4 / 9)$ & $69^{*}$ \\
\hline Com
\end{tabular}

Complete remissions are indicated in brackets. ${ }^{*} p<0.005$.

doi:10.1371/journal.pone.0080836.t001 fotemustine alone induced a dramatic increase of $\mathrm{Bcl}-2$ in the MM66 xenograft, and an increase of the Mcl-1 protein in the MP41 and MM66 xenografts. Consequently, the expression of both Bcl-2 and Mcl-1 was highly increased after concomitant administration of fotemustine and S44563 in the MM66 xenograft (Figure 5).

In order to evaluate in vivo apoptosis induction, we have studied cleaved caspase-3 expression before and after S44563 +/fotemustine administration. Tumor samples have also been collected at the time of mice sacrifice. We did not detect significant increase of activated caspase- 3 in the four treated UM xenografts (data not shown). Similarly, we did not observe LC3-positive tumor cells before and after treatments (data not shown), as in in vitro experiments, except in one MM66 tumor among five xenografts treated by S44563 $(50 \mathrm{mg})$, where a unique islet of about 20 positive cells has been observed.

\section{Discussion}

Using four well-characterized uveal melanoma PDXs, we have shown that a specific Bcl-2/Bcl- $\mathrm{X}_{\mathrm{L}}$ inhibitor only had a moderate efficacy when administered alone, except in one model (MP41) 
Table 2. Overall and median survival after combination of $\$ 44563$ and fotemustine.

\begin{tabular}{|c|c|c|c|c|c|c|c|}
\hline Models & Criteria & Control & S-50 & F-30 & $F-30+S-50$ & F-30/S-100 & $\begin{array}{l}\text { F-30+S-50/ } \\
\text { S-100 }\end{array}$ \\
\hline \multirow[t]{2}{*}{ MP41 } & OS (78) & $8 \%$ & $14 \%$ & $21 \%$ & $77 \%$ & $77 \%$ & $69 \%$ \\
\hline & Median S. & 44 & 61 & $72^{*}$ & $102^{*}$ & & \\
\hline \multirow[t]{3}{*}{ MP77 } & OS (85) & $0 \%$ & $0 \%$ & $0 \%$ & $12 \%$ & $48 \%$ & $67 \%$ \\
\hline & Median S. & 7 & 11 & 67 & 59 & 82 & $>85$ \\
\hline & Prolonged CR (85) & I & I & $20 \%$ & $20 \%$ & $40 \%$ & $60 \%$ \\
\hline \multirow[t]{2}{*}{ MM26 } & OS (117) & $0 \%$ & $0 \%$ & $90 \%$ & $89 \%$ & I & I \\
\hline & CR rate & $0 \%$ & $0 \%$ & $0 \%$ & $29 \%$ & & \\
\hline
\end{tabular}

Abbreviations: F-30/S-50, fotemustine followed by S44563 adminstration since day 43; OS (day), overall survival observed at the indicated day; Median S, median survival in days since start of treatment.

* $\mathrm{F}-30$ versus $\mathrm{F}-30+\mathrm{S}-50$ or $\mathrm{F}-30 / \mathrm{S}-100: \mathrm{p}=0.04$

F-30/S-100 versus F-30+S-50/S-100: $p=0.038$

doi:10.1371/journal.pone.0080836.t002

with a clear dose-dependent in vivo efficacy. However, we have shown that this $\mathrm{Bcl}-2 / \mathrm{Bcl}-\mathrm{X}_{\mathrm{L}}$ inhibition significantly increased the antitumor activity of fotemustine in these preclinical models. Indeed, in 3 out of the 4 tested xenografts (MP41, MP77, and MM66), S44563 increased tumor growth inhibition when combined to fotemustine in comparison to fotemustine alone. It also increased the complete remission rate (MM26 model) and the overall survival (MP41 model). Overall, these data strongly suggest that targeting $\mathrm{Bcl}-2 / \mathrm{Bcl}-\mathrm{X}_{\mathrm{L}}$ in combination with fotemustine significantly improves, in human UM xenografts, response to the alkylating agent administered alone.

Hence, our treatment combination significantly enhanced efficacy compared to treatment with either agent alone, confirming positive data reported with the BH3-mimetic ABT-737 and various chemotherapies such as fotemustine [31], temozolomide [31,32], melphalan [33], cytosine arabinoside [34], gemcitabine [35], actinomycine D [36], carboplatin [37], and others, or with Bcl-2 antisense and cyclophosphamide [38] or chlorambucil [39]. In the MM66 xenograft, this observation could be explained by the fact that fotemustine highly increased Bcl-2 expression that could be therefore more efficiently inhibited. In few reports, it has been shown that this effect was p53-independent but related to the pro-apoptotic protein Noxa $[31,32,40]$, which inactivates other Bcl-2-family members such as Mcl-1 or Al proteins [40]. The balance of $\mathrm{Bcl}-2 / \mathrm{Mcl}-1$ proteins has also been largely shown to impact the efficacy of ABT-737 [34-36,41,42], suggesting that modulation of Noxa and Mcl-1 could be used as a strategy for sensitizing tumor cells to ABT-737 [31,43]. Another predictive marker could be Bcl- $\mathrm{X}_{\mathrm{L}}$ expression and indeed in our in vivo experiments, the best responding xenografts were characterized by higher $\mathrm{Bcl}-\mathrm{X}_{\mathrm{L}}$ expression, suggesting that specifically targeting the $\mathrm{Bcl}-\mathrm{X}_{\mathrm{L}}$ protein may be an efficient therapeutic approach by itself. Such an observation is confirmed by the report of Jain and MeyerHermann who showed that inhibition of $\mathrm{Bcl}_{\mathrm{X}}$ may decrease the reparation of DNA damages induced by carboplatin [37].

One other mechanism leading to the synergistic effect between a Bcl-2 inhibitor and temozolomide could be the specific induction of autophagic cell death, as recently reported [44,45]. In our in vitro experiments testing the effect of S44563 in 3 human UM cell lines, S44563 did not modify the proportion and the total amount of

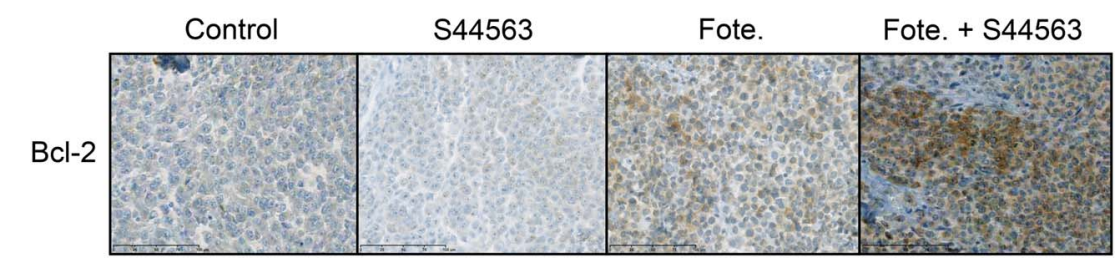

$\mathrm{Bcl}-\mathrm{X}_{\mathrm{L}}$

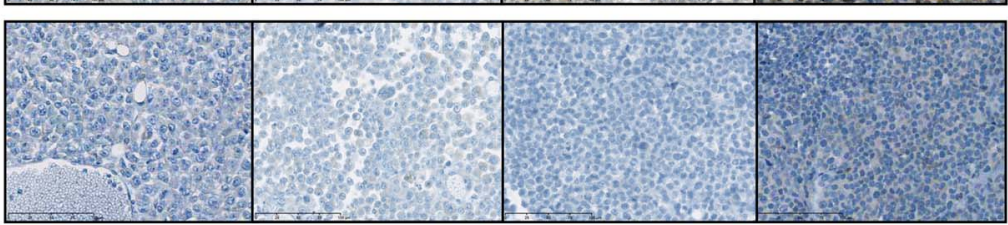

Mcl-1

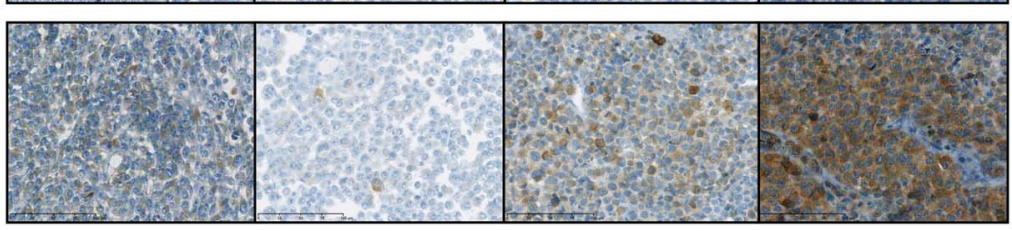

Figure 5. Immunohistochemical analyses under S44563 administration. Immunohistochemical analyses of the MM66 UM xenograft after S44563, fotemustine, or S44563+fotemustine.

doi:10.1371/journal.pone.0080836.g005 
cleaved LC3 protein. Whereas we have not confirmed the modulation of autophagy, further in vivo experiments are needed to more extensively study the impact of such Bcl-2/Bcl- $\mathrm{X}_{\mathrm{L}}$ inhibitor in human uveal melanoma tumors.

Taking together, our results clearly demonstrate that Bcl-2/Bcl$\mathrm{X}_{\mathrm{L}}$ targeting is a promising therapeutic approach for uveal melanoma. Despite a modest efficacy when used alone, S44563 significantly increased efficacy of fotemustine. Even intra-arterial hepatic administration of this alkylating agent remains poorly efficient in UM patients, both in an adjuvant setting after proton beam irradiation [46] and in metastatic evolution [47]. It is therefore required to improve its efficacy and reverse mechanisms of resistance. Targeting specific members of the Bcl-2 family, such as Bcl-2 and $\mathrm{Bcl}-\mathrm{X}_{\mathrm{L}}$ proteins, could be of high clinical interest. In our in vivo experiments, we have evaluated this targeted approach in relevant preclinical models and showed that both in concomitant and differed administration, S44563 were able to increase the effect of fotemustine. Our data therefore suggest that S44563 could probably be evaluated in both adjuvant and metastatic settings of UM patients. In the first clinical situation, genomic features of UM tumors clearly defined prognostic outcome of the patients $[48,49]$, allowing a relevant discrimination and selection of poor prognosis cases, and, in the second clinical situation, the overall prognosis remains very poor. Altogether, our results emphasize a potential therapeutic interest for targeting Bcl-2/ Bcl-X $\mathrm{X}_{\mathrm{L}} \mathrm{UM}$ patients.

\section{Supporting Information}

Figure S1 Chemical structure of S44563. (TIF)

Figure S2 Viability of the 3 uveal melanoma xenograft-derived cell lines MP41, MM26, and MM66 after 24 hours incubation with S44563. Viability of treated cells was determined by the $50 \%$ inhibitory concentration induced by S44563 using a WST-1 test. A two-way ANOVA with Bonferroni post-test was then performed (* means a $\mathrm{p}<0.05)$.

(TIF)

Figure S3 Overall response rate (ORR) after S44563 administration. A. ORR of mice treated by $\mathrm{S} 44563$ at a dose of $50 \mathrm{mg} / \mathrm{kg}$

\section{References}

1. Salmon RJ, Levy C, Plancher C, Dorval T, Desjardins L, et al. (1998) Treatment of liver metastases from melanoma by combined surgery-chemotherapy. Eur J Surg Oncol 24: 127-130.

2. Kujala E, Mäkitie T, Kivelä T (2003) Very long-term prognosis of patients with malignant uveal melanoma. Ophthalmology 110: 962-965.

3. Augsburger JJ, Corrêa ZM, Shaikh AH (2009) Effectiveness of treatments for metastatic uveal melanoma. Am J Ophthalmol 148: 119-127.

4. Hanahan D, Weinberg RA (2000) The hallmarks of cancer. Cell 100: 57-70.

5. Danial NN, Korsmeyer SJ (2004) Cell death: critical control points. Cell 116: 205-219.

6. Mooy CM, Luyten GP, de Jong PT, Luider TM, Stijnen T, et al. (1995) Immunohistochemical and prognostic analysis of apoptosis and proliferation in uveal melanoma. Am J Pathol 147: 1097-1104.

7. Jay V, Yi Q Hunter WS, Zielenska M (1996) Expression of bcl-2 in uveal malignant melanoma. Arch Pathol Lab Med 120: 487-488.

8. Coupland SE, Bechrakis N, Schüler A, Anagnostopoulos I, Hummel M, et al. (1998) Expression patterns of cyclin D1 and related proteins regulating G1-S phase transition in uveal melanoma and retinoblastoma. Br J Ophthalmol 82: 961-970.

9. Chana JS, Wilson GD, Cree IA, Alexander RA, Myatt N, et al. (1999) c-myc, p53, and Bcl-2 expression and clinical outcome in uveal melanoma. Br J Ophthalmol 83: 110-114.

10. Lawry J, Currie Z, Smith MO, Rennie IG (1999) The correlation between cell surface markers and clinical features in choroidal malignant melanomas. Eye 13: 301-308.

11. Sulkowska M, Famulski W, Bakunowicz-Lazarczyk, Chyczewski L, Sulkowski S (2001) Bcl-2 expression in primary uveal melanoma. Tumori 87: 54-57. per injection. B. ORR of mice treated by $\mathrm{S} 44563$ at a dose of $100 \mathrm{mg} / \mathrm{kg}$ per injection. The ORR was defined as the relative tumor volume variation (RTVV) of each S44563-treated mouse calculated from the following formula: [(Vt/Vc)-1], where $\mathrm{Vt}$ is the volume of the treated mouse and $\mathrm{V}_{\mathrm{c}}$ the median volume of the corresponding control group at a time corresponding to the end of treatment.

(TIF)

Figure S4 Immunohistochemical analyses under S44563 administration. A. Bcl-2 expression determined by immunohistochemical analyses of the MM66 xenograft after S44563 in vivo administration. B. Determination of Bcl-2-positive tumor cells in the 4 UM xenografts after S44563 administration. C. Determination of $\mathrm{Bcl}-\mathrm{X}_{\mathrm{L}}$-positive tumor cells in the 4 UM PDXs after S44563 administration. D. Determination of Mcl-1-positive tumor cells in the 4 UM xenografts after S44563 administration.

(TIF)

Table S1 Biological characteristics of the 4 UM PDXs. (DOC)

Table S2 Immunohistochemical analyses of the 4 UM PDXs. (DOC)

Table S3 IHC scores under S44563 +/- fotemustine administration.

(DOG)

\section{Acknowledgments}

We are grateful to Dr Jean François Boivin for histological interpretation. We also would like to thank Marie-Hélène Donnadieu, Ahmed Dahmani, Johann Richard and Michel Suc for their technical assistance, Marika Pla and colleagues for animal facilities support.

\section{Author Contributions}

Conceived and designed the experiments: DD. Performed the experiments: FN CdM GL GC AB DV OG LdP. Analyzed the data: FN CdM LKB XSG OG LD SPN SD DD. Contributed reagents/materials/analysis tools: AP BL. Wrote the paper: DD.

12. Hussein MR (2005) Analysis of Bcl-2 protein expression in choroidal melanomas. J Clin Pathol 58: 486-489.

13. Némati F, Sastre-Garau X, Laurent C, Couturier J, Mariani P, et al. (2010) Establishment and characterization of a panel of human uveal melanoma xenografts derived from primary and/or metastatic tumors. Clin Cancer Res 16: 2352-2362.

14. Resik SW (2005) Promoting apoptosis as a strategy for cancer drug discovery. Nat Rev Cancer 5: 876-885.

15. Bedikian AY, Millward M, Pehamberger H, Conry R, Gore M, et al. (2006) Bcl2 antisense (oblimersen sodium) plus dacarbazine in patients with advanced melanoma: the Oblimersen Melanoma Study Group. J Clin Oncol 24: 47384745 .

16. O'Brien S, Moore JO, Boyd TE, Larratt LM, Skotnicki AB, et al. (2009) 5-year survival in patients with relapsed or refractory chronic lymphocytic leukemia in a randomized, phase III trial of fludarabine plus cyclophosphamide with or without oblimersen. J Clin Oncol 27: 5208-5212.

17. Rudin GM, Salgia R, Wang X, Hodgson LD, Masters GA, et al. (2008) Randomized phase II Study of carboplatin and etoposide with or without the bcl-2 antisense oligonucleotide oblimersen for extensive-stage small-cell lung cancer: CALGB 30103. J Clin Oncol 26: 870-876.

18. Chanan-Khan AA, Niesvizky R, Hohl RJ, Zimmerman TM, Christiansen NP, et al. (2009) Phase III randomised study of dexamethasone with or without oblimersen sodium for patients with advanced multiple myeloma. Leuk Lymphoma 50: 559-565.

19. Sternberg CN, Dumez H, Van Poppel H, Skoneczna I, Sella A, et al. (2009) Docetaxel plus oblimersen sodium (Bcl-2 antisense oligonucleotide): an EORTC 
multicenter, randomized phase II study in patients with castration-resistant prostate cancer. Ann Oncol 20: 1264-1269.

20. Oltersdorf T, Elmore SW, Shoemaker AR, Armstrong RC, Augeri DJ, et al. (2005) An inhibitor of Bcl-2 family proteins induces regression of solid tumours. Nature 435: 677-681.

21. Tse C, Shoemaker AR, Adickes J, Anderson MG, Chen J, et al. (2008) ABT-263: a potent and orally bioavailable Bcl-2 family inhibitor. Cancer Res 68: $3421-$ 3428 .

22. Nguyen M, Marcellus RC, Roulston A, Watson M, Serfass L, et al. (2007) Small molecule obatoclax (GX15-070) antagonizes MCL-1 and overcomes MCL-1mediated resistance to apoptosis. Proc Natl Acad Sci U S A 104: 19512-19517.

23. Ackler S, Mitten MJ, Foster K, Oleksijew A, Refici M, et al. (2010) The Bcl-2 inhibitor ABT-263 enhances the response of multiple chemotherapeutic regimens in hematologic tumors in vivo. Cancer Chemother Pharmacol 66: 869-880.

24. Tan N, Malek M, Zha J, Yue P, Kassees R, et al. (2011) Navotoclax enhances the efficacy of taxanes in non-small cell lung cancer models. Clin Cancer Res 17: 1394-1404.

25. Loriot Y, Mordant P, Dugué D, et al. (2012) Radiation enhances the efficacy of Bcl-2 and Bcl- $\mathrm{X}_{\mathrm{L}}$ inhibition in small cell lung cancer. A new concept of using radiation for targeted therapy through contextual oncogene addiction. Am Assoc Cancer Res Annual congress: poster 4891.

26. Gandhi L, Camidge DR, Ribeiro de Oliveira M, Bonomi P, Gandara D, et al. (2011) Phase I study of Navitoclax (ABT-263), a novel Bcl-2 family inhibitor, in patients with small-cell lung cancer and other solid tumors. J Clin Oncol 29: 909-916.

27. Wilson WH, O’Connor OA, Czuczman MS, LaCasce AS, Gerecitano JF, et al. (2011) Nanitoclax, a targeted high-affinity inhibitor of Bcl-2, in lymphoid malignancies: a phase 1 dose-escalation study of safety, pharmacokinetics, pharmacodynamics, and antitumour activity. Lancet Oncol 11: 1149-1159.

28. Guo LJ, Wu ZY, Zhang S, Zheng JL, Zheng hL (2003) Effect of bcl-2 antisense oligonucleotides on multidrug resistance of cultured uveal melanoma cells. Zhonghua Yan Ke Za Zhi 39: 73-76.

29. Laurent C, Gentien D, Piperno-Neumann S, Némati F, Nicolas A, et al. (2013) Patient-derived xenografts recapitulate molecular features of human uveal melanomas. Mol Oncol 7: 625-636.

30. Kim KW, Moretti L, Mitchell LR, Jung DK, Lu B (2009) Combined Bcl-2/ mammalian target of rapamycin inhibition leads to enhanced radiosensitization via induction of apoptosis and autophagy in non-small cell lung tumor xenograft model. Clin Cancer Res 15: 6096-6105.

31. Weber A, Kirejczyk Z, Potthoff S, Ploner C, Häcker G (2009) Endogenous Noxa determines the strong proapoptotic synergism of the BH3-mimetic ABT-737 with chemotherapeutic agents in human melanoma cells. Translat Oncol 2: 7383.

32. Reuland SN, Goldstein NB, Partyka KA, Cooper DA, Fujita M, et al. (2011) The combination of BH3-mimetic ABT-737 with the alkylating agent temozolomide induces strong synergistic killing of melanoma cells independent of p53. PLoS One 6: e24294.

33. Trudel S, Stewart AK, Li Z, Shu Y, Liang SB, et al. (2007) The Bcl-2 family protein inhibitor, ABT-737, has substantial antimyeloma activity and shows synergsitic effect with dexamethasone and melphalan. Clin Cancer Res 13: 621629.

34. Touzeau C, Dousset C, Bodet L, Gomez-Bougie P, Bonnaud S, et al. (2011) ABT-737 induces apoptosis in mantle cell lymphoma cells with a Bcl-2 $2^{\text {high }} / \mathrm{Mcl}-$ $1^{\text {low }}$ profile and synergizes with other antineoplastic agents. Clin Cancer Res 17: 5973-5981.

35. Zhou Z, Zhang C, Xia C, Chen W, Zhu H, et al. (2011) Synergistic antitumor activity of gemcitabine and ABT-737 in vitro and in vivo through disrupting the interaction of USP9X and Mcl-1. Mol Cancer Ther 10: 1264-1275.

36. Xu H, Krystal GW (2010) Actinomycin D decreases Mcl-1 expression and acts synergistically with ABT-737 against small cell lung cancer cell lines. Clin Cancer Res 16: 4392-4400.

37. Jain HV, Meyer-Hermann M (2011) The molecular basis of synergism between carboplatin and ABT-737 therapy targeting ovarian carcinomas. Cancer Res 71: 705-715.

38. Simoes-Wüst AP, Schürpf T, Hall J, Stahel RA, Zangemeister-Wittke U (2002) Bcl-2:bcl-xL bispecific antisense treatment sensitizes breast carcinoma cells to doxorubicin, paclitaxel and cyclophosphamide. Breast Cancer Res Treat 76: 157-166.

39. Pepper C, Hooper K, Thomas A, Hoy T, Bentley P (2001) Bcl-2 antisense oligonucleotides enhance the cytotoxicity of chlorambucil in B-cell chronic lymphocytic leukaemia cells. Leuk Lymphoma 42: 491-498.

40. Zall H, Weber A, Besch R, Zantl N, Häcker G (2010) Chemotherapeutic drugs sensitize human renal cell carcinoma cells to ABT-737 by a mechanism involving the Noxa-dependent inactivation of Mcl-1 or A1. Mol Cancer 9: 164.

41. Yecies D, Carlson NE, Denq J, Letai A (2010) Acquired resistance to ABT-737 in lymphoma cells that up-regulate Mcl-1 and BFL-1. Blood 115: 3304-3313.

42. Al-Harbi S, Hill BT, Mazumder S, Singh K, Devecchio J, et al. (2011) An antiapoptotic Bcl-2 family expression index predicts the response of chronic lymphocytic leukemia to ABT-737. Blood 118: 3579-3590.

43. Lucas KM, Mohana-Kumaran N, Lau D, Zhang XD, Hersey P, et al. (2012) Modulation of NOXA and MLC-1 as a strategy for sensitizing melanoma cells to the BH3-mimetic ABT-737. Clin Cancer Res 18: 783-795.

44. Voss V, Senft C, Lang V, Ronellenfitsch MW, Steinbach JP, et al. (2010) The pan-Bcl-2 inhibitor (-)-gossypol triggers autophagic cell death in malignant glioma. Mol Cancer Res 8: 1002-1016.

45. Malik SA, Orhon I, Morselli E, Criollo A, Shen S, et al. (2011) BH3 mimetics activate multiple pro-autophagic pathways. Oncogene 30: 3918-3929.

46. Voelter V, Schalenbourg A, Pampallona S, Peters S, Halkic N, et al. (2008) Adjuvant intra-arterial hepatic fotemustine for high-risk uveal melanoma patients. Melanoma Res 18: 220-224.

47. Peters S, Voelter V, Zografos L, Pampallona S, Popescu R, et al. (2006) Intraarterial hepatic fotemustine for the treatment of liver metastases from uveal melanoma: experience in 101 patients. Ann Oncol 17: 578-583.

48. Prescher G, Borngeld N, Horsthemke B, Becher R (1992) Chromosomal aberrations defining uveal melanoma of poor prognosis. Lancet 339: 691-692.

49. Trolet J, Hupé P, Huon I, Lebigot I, Decraene C, et al. (2009) Genomic profiling and identification of high-risk uveal melanoma by array cgh analysis of primary tumors and liver metastases. Invest Ophthalmol Vis Sci 50: 2572-2580. 